\title{
"Superdesignação" de professores na rede estadual de ensino de Minas Gerais
}

\author{
Marina Alves Amorim' \\ Ana Paula Salej' \\ Brenda Borges Cambraia Barreiros'
}

\section{RESUMO}

Este artigo apresenta parte dos resultados de pesquisa sobre os professores da rede estadual de ensino de Minas Gerais. Explorando o banco de dados da Secretaria de Estado de Educação de Minas Gerais, a pesquisa revelou quantos são os professores efetivos e contratados por tempo determinado nas escolas do estado de Minas Gerais e como os números de vínculos de trabalho oscilaram entre 2009 e 2014. Trata-se de informação aparentemente simples, mas de difícil acesso, o que a torna preciosa. O quadro de "superdesignação" relevado é, além de surpreendente, um problema grave na gestão da educação em Minas Gerais, que impacta na qualidade da educação pública e clama por um redirecionamento da ação do estado no campo educacional.

\section{PALAVRAS-CHAVE}

professores; vínculo de trabalho; rede estadual de ensino de Minas Gerais.

'Fundação João Pinheiro, Belo Horizonte, MG, Brasil. 


\title{
"OVERNOMINATION" OF TEACHERS AT THE PUBLIC EDUCATION SYSTEM OF THE STATE OF MINAS GERAIS (REDE ESTADUAL DE ENSINO DE MINAS GERAIS)
}

\begin{abstract}
This article presents a part of the results of a research with the teachers from the public education system in the state of Minas Gerais. Based on the exploration of the database of Minas Gerais'State Education Department, the research revealed how many teachers have permanent employment contracts and how many of them have temporary contracts. Moreover, it shows how these numbers oscillated between 2009 and 2014. This might seem to be simple information, but it is rather difficult to be accessed, what makes it valuable. Besides surprising, the picture of "overnomination", revealed by this study, is a major problem in the education management of Minas Gerais. It affects the quality of public education and claims for a rearrangement by the state in this field.
\end{abstract}

KEYWORDS

teachers; employment contracts; public education system of the state of Minas Gerais.

\section{"SUPERDESIGNACIÓN" DE PROFESORES EN LA RED ESTADUAL DE ENSEÑANZA DE MINAS GERAIS}

\section{RESUMEN}

Este artículo presenta parte de los resultados de investigación sobre los profesores de la red estadual de enseñanza de Minas Gerais. A partir de la indagación en el Banco de Datos de la Secretaría de Estado de Educación de Minas Gerais de Minas Gerais, la investigación reveló cuantos son los profesores contratados definitivamente y cuantos contratados temporalmente en las escuelas del Estado de Minas Gerais, y cómo esos números oscilaron entre 2009 y 2014. Se trata de una información aparentemente simple, pero que, por ser de difícil acceso, es muy valiosa. El resultado de "superdesignación" destacado es, además de sorprendente, un problema grave en la gestión de la educación en Minas Gerais, que impacta en la calidad de la educación pública y que clama por una reorientación de la acción del Estado en el campo educacional.

PALABRAS CLAVES

profesores; vínculo de trabajo; red estadual de enseñanza de Minas Gerais. 


\section{INTRODUÇÃO}

Este artigo apresenta parte dos resultados alcançados no desenvolvimento de projeto de pesquisa acerca da rede estadual de ensino de Minas Gerais. Seu objetivo, primeiramente, era debruçar-se sobre o banco de dados da Secretaria de Estado de Educação de Minas Gerais (SEE/MG) e elaborar um retrato da profissão docente no estado de Minas Gerais no tocante aos vínculos de trabalho dos professores. Nessa rede de ensino, afinal, quantos são os professores efetivos e quantos são os contratados por tempo determinado? Como esses números oscilaram entre 2009 e 2014?

Os achados a esse respeito são apresentados e analisados, detalhadamente, ao longo do artigo, sendo possível se fazer uma justaposição a outros trabalhos, com diferentes recortes, já elaborados ou em elaboração. $\mathrm{O}$ artigo em tela traz à tona e procura compreender dados que, embora aparentemente simples, são de difícil acesso, o que os torna extremamente preciosos. Durante a sua construção, a revelação do pequeno número de professores efetivos na rede de ensino surpreendeu, "escancarando" um problema grave existente na gestão da Educação em Minas Gerais que, sem dúvida, impacta na qualidade da educação pública e que clama, portanto, por um redirecionamento da ação do estado no campo educacional.

Para a elaboração do quadro acerca dos vínculos de trabalho da profissão docente na referida rede de ensino, foram levantados dados quantitativos na Assessoria de Planejamento (ASSPLAN) da SEE-MG e na Diretoria de Informações Gerenciais (DIG) da Superintendência de Normas e Informações de Pessoal (SNIP) da Subsecretaria de Gestão de Recursos Humanos (SGRH) da SEE-MG. Os dados coletados e explorados no artigo são os números de cargos de professores efetivos, designados e efetivados da rede estadual de ensino de Minas Gerais entre 2009 e 2014 (Minas Gerais, 2015b). ${ }^{1}$

O recorte temporal estabelecido, inicialmente, levou em consideração que o sistema de armazenamento de dados de recursos humanos do governo de Minas Gerais, o Sistema Integrado de Administração de Pessoal (SISAP), foi criado em 2007, sendo então interessante levantar todas as informações disponíveis até o momento da realização da coleta de dados, no início do segundo semestre de 2015. Todavia, como as referências aos anos de 2007,2008 e 2015 não estavam completas, optou-se por desconsiderar esses anos, restringindo o recorte temporal entre 2009 e 2014 (Minas Gerais, 2015b).

Também foi realizada uma entrevista de história oral temática com o professor Antônio David de Souza Júnior, subsecretário de Gestão de Recursos Humanos da SEE-MG, acerca dos resultados alcançados pelo trabalho com os dados

1 A SEE-MG forneceu os dados em vários arquivos de bloco de notas, que foram transferidos para o Statistical Package for the Social Sciences (SPSS), para que pudessem ser trabalhados. 
quantitativos. ${ }^{2}$ É de responsabilidade da sua pasta a organização e a realização de concursos públicos, assim como procedimentos para a nomeação e a aposentadoria, além de tudo que diz respeito ao desenrolar da carreira dos profissionais da educação básica (Souza Júnior, 2016). ${ }^{3}$

Por fim, foram levantados documentos que ajudaram a integrar o corpus analisado no desenvolvimento da pesquisa: a Constituição de 1988 (Brasil, 1988); o Plano Nacional de Educação (Brasil, 2014); a lei estadual n. 10.254, de 20 de julho de 1990 (Minas Gerais, 1990); a lei estadual n. 100, de 5 de novembro de 2007 (Minas Gerais, 2007); e a lei estadual n. 18.185, de 4 de junho de 2009 (Minas Gerais, 2009). Esses documentos serviram para elucidar o que diz a legislação e as políticas educacionais acerca do corpo docente das redes de ensino públicas.

\section{O PONTO DE PARTIDA}

Lapo e Bueno (2003) estudaram o abandono da carreira na escola pública e/ou da profissão docente por professores da rede estadual de ensino de São Paulo. Em 1995, quando iniciaram a pesquisa, as autoras trabalhavam com a hipótese de que a cada ano, no estado de São Paulo, mais professores estaduais desistiam de seus postos de trabalho e mesmo da profissão - hipótese esta construída com base nas informações veiculadas pela mídia e também em observações realizadas nas escolas nas quais atuavam. As autoras buscavam testar essa hipótese, além de compreender $\mathrm{a}(\mathrm{s})$ dinâmica(s) desse(s) abandono(s), questionando quais os fatores de ordem externa e quais as disposições internas individuais eram determinantes, em outras palavras, buscando desvelar como os fatos e os acontecimentos eram percebidos e vivenciados pelos professores e como tal combinação desencadeava o(s) processo(s).

$\mathrm{Na}$ primeira etapa do trabalho, com o intuito de se certificar da presença e das proporções do fenômeno intuído, Lapo e Bueno (2003) levantaram dados sobre a exoneração de professores efetivos da rede estadual de ensino de São Paulo, entre os anos de 1990 e 1995, na Secretaria da Educação do Estado de São Paulo (SEE/ $\mathrm{SP})$. As pesquisadoras confirmaram, então, a hipótese inicial: no decorrer dos anos

2 Antônio David de Souza Júnior é licenciado em matemática, especialista em matemática superior e possui mestrado inconcluso em matemática. Sua trajetória profissional na área da educação iniciou-se na educação básica, sendo que, hoje, além de atuar na gestão educacional, é professor universitário em uma instituição particular de ensino superior. Especificadamente em gestão, foi diretor de uma escola municipal de Belo Horizonte e sua excelente atuação o levou a ser convidado para trabalhar na Secretaria Municipal de Educação da Prefeitura de Belo Horizonte (SMED/PBH), quando a cidade era administrada pelo prefeito Patrus Ananias (1993-1996). Na SMED, atuou com formação continuada de professores, chegando a ocupar, posteriormente, os postos de secretário adjunto e, entre 2001 e 2004, secretário da Educação. O professor David assumiu seu atual cargo de trabalho, em 2015, quando Fernando Pimentel foi eleito governador de Minas Gerais.

3 A elaboração do roteiro de entrevista e sua gravação seguiram as normas técnicas apresentadas no manual de história oral do Centro de Pesquisa e Documentação de História Contemporânea do Brasil (CPDOC) da Fundação Getúlio Vargas (FGV), elaborado por Alberti (1989). 
estudados, os pedidos de exoneração cresceram em torno de 300\%, o que significava um aumento médio anual de $43 \%{ }^{4}$ Quando agrupados por região (São Paulo Capital, Grande São Paulo e Interior do Estado) e por categoria docente (professor I ou PI, professor II ou PII e professor III ou PIII), ${ }^{5}$ os dados mostravam-se bastante discrepantes. Na cidade de São Paulo, os números absolutos de exoneração eram bem mais elevados. Foram 1.850 pedidos ao todo, ao longo dos cinco anos, o que equivale a uma média anual de 88 pedidos por Delegacia de Ensino, ${ }^{6}$ quase o dobro, se comparada à média anual por delegacias da região metropolitana (total 1.073; média 48), que englobava 38 municípios, e mais que o triplo, se comparada à média anual por delegacias do interior do estado (total 2.467; média 24). ${ }^{7}$

Considerando o agrupamento por categoria docente, curiosamente o professor PI, que ocupava o nível mais baixo na hierarquia educacional e recebia a menor remuneração, apresentava menor exoneração em números absolutos do que o professor PIII. Dos 47.666 PI efetivos, 2.308 pediram exoneração; dos 63 PII, nenhum pediu exoneração; dos 33.370 PIII efetivos, 3.082 pediram exoneração. ${ }^{8}$ Nesse caso, Lapo e Bueno (2003, p. 70) indagam:

[...] o que mantém esses professores trabalhando na rede estadual de ensino? Seria pelo fato de trabalharem com uma única classe, ou no máximo com duas, geralmente em uma mesma escola, e, assim, criarem vínculos mais fortes com os alunos, portanto mais dificeis de serem rompidos? Ou seria pela falta de um diploma de nível superior e, por isso, terem menos chances profissionais no mercado de trabalho?

Há de se destacar que, segundo Lapo e Bueno (2003), em 1995, a rede estadual de ensino de São Paulo contava com 230 mil professores, dos quais apenas 78.135 , ou seja, $34 \%$ eram efetivos. Dessa maneira, ao contrário do que se pode supor, em São Paulo a maioria dos professores estaduais é contratada por tempo determinado, o que certamente tem consequências do ponto de vista educacional.

Na segunda etapa da pesquisa de Lapo e Bueno (2003), um questionário foi aplicado a 158 ex-professores da Delegacia de Ensino que apresentava o maior índice

4 Lapo e Bueno (2003) não informaram o total de pedidos de exoneração em números absolutos por ano, tampouco o que esses dados representavam em percentuais do total de professores efetivos da rede de ensino pesquisada.

5 PI designava o docente das então quatro séries iniciais do antigo ensino de $1^{\circ}$ grau; PII, o docente das então quatro séries finais do antigo ensino de $1^{\circ}$ grau; e, por fim, PIII designava o docente do antigo ensino de $2^{\circ}$ grau.

6 No momento em que a pesquisa de Lapo e Bueno foi realizada, ainda se utilizava a expressão Delegacia de Ensino, sendo posteriormente usada a nomenclatura Diretoria de Ensino.

7 Lapo e Bueno (2003) também não informaram o que esses números absolutos representavam em percentuais, considerando os números totais recortados por região.

8 Considerando o número total de professores e o número total de exoneraçỗes por categoria docente, é possível calcular o percentual de exoneração, a saber: $4,84 \%$, no que concerne à categoria PI; $0 \%$, no que concerne à categoria PII; e 9,23\%, no que concerne à categoria PIII. 
de evasão docente do estado de São Paulo, com a intenção de recolher dados que permitissem construir um perfil desses ex-professores e compreender os processos por eles experimentados que culminaram com o abandono da carreira na escola pública e, possivelmente, da profissão docente. Todavia, apenas 29 desses profissionais devolveram o questionário preenchido, e muitos deles haviam abandonado a referida rede de ensino no momento em que estavam prestes a concluir ou já tinham concluído a pós-graduação, ou seja, quando se encontravam envolvidos com atividades de pesquisa, o que, em nossa opinião, são fatores que enviesam os resultados alcançados nesse momento. Por fim, Lapo e Bueno (2003) entrevistaram 16 professores que pediram exoneração do cargo na rede estadual de ensino de São Paulo.

No que concerne à análise das entrevistas de história oral, vale ressaltar a tese defendida pelas autoras. Deixar de ser professor, tal como se tornar professor, é um processo de constituição dos sujeitos que não acontece bruscamente, da noite para o dia. E, em meio a esse processo, o abandono definitivo do trabalho é precedido de outros tipos de abandonos: temporários, que incluem faltas, licenças curtas e licenças sem vencimento; especiais, ou seja, remoção ou transferência e acomodação, quando "[...] não há o distanciamento físico, uma vez que o professor comparece à escola, ministra as aulas, cumpre as obrigações burocráticas, porém executa essas atividades dentro de um limite que representa o mínimo necessário para manter-se no emprego" (Lapo e Bueno, 2003, p. 84).

O projeto de pesquisa acerca da rede estadual de ensino de Minas Gerais foi elaborado sob o impacto da leitura dos resultados alcançados por Lapo e Bueno (2003). Tal projeto propunha replicar, em Minas Gerais, o que essas pesquisadoras haviam realizado em São Paulo, com algumas modificações.

\section{PROFESSORES EFETIVOS, DESIGNADOS E EFETIVADOS EM NÚMEROS}

Em Minas Gerais, os professores constituem um enorme contingente no que se refere a recursos humanos. Em 2014, eram 164.808 cargos efetivos, designados e efetivados de professor na rede estadual de ensino desse estado.

O grupo de professores efetivos é formado por aqueles que, uma vez aprovados em concurso público, ingressaram na carreira docente, tal como preconiza a Constituição da República Federativa do Brasil (Brasil, 1988). Entretanto, os profissionais efetivos podem entrar em licença, afastar-se do trabalho com ou sem remuneração, ser deslocados por ajustamento funcional, entre outros. Assim, para assegurar o funcionamento das escolas estaduais, a lei estadual n. 10.254/1990 (Minas Gerais, 1990) autorizou a contratação de professores por período determinado. O grupo de professores designados é então composto de professores temporários, que, de acordo com a lei estadual n.18.185/2009 (Minas Gerais, 2009), além de possuírem vínculo precário, gozam de menos benefícios que os colegas efetivos. Por fim, mecanismos legais, como é o caso da lei estadual n. 100/2007 (Minas Gerais, 2007), terminaram por criar um terceiro tipo de vínculo de trabalho para os professores do estado de Minas Gerais e, logo, um terceiro agrupamento, ao tornar efetivas no serviço público pessoas sem a realização de concurso. $\mathrm{O}$ grupo de professores efetivados da rede 
estadual de ensino de Minas Gerais é formado por esses professores, que, depois de trabalharem por alguns anos como designados em escolas estaduais, tornaram-se efetivos pela ação do legislativo.

Importante notar que professores efetivos e efetivados possuem, a princípio, contratos de trabalho estáveis. Todavia, suas formas de ingresso na rede de ensino são distintas, uma vez que apenas os efetivos percorrem o caminho reconhecido constitucionalmente - o concurso público. Sendo assim, da mesma maneira que os profissionais foram alçados a efetivos pela mão do legislativo, os efetivados podem deixar de sê-lo a qualquer momento pela mão da justiça, e isso costuma acontecer. $\mathrm{O}$ terceiro grupo de professores apresentado possui, por assim dizer, uma estabilidade precária, o que justifica agrupá-lo à parte.

A Tabela 1 apresenta a rede estadual de ensino de Minas Gerais em números absolutos, entre 2009 e 2014, por agrupamento docente. Nota-se que, em 2009, eram 72.428 cargos efetivos de professor, 34.955 cargos designados e 62.766 cargos efetivados, totalizando 170.149 cargos de professor. Cinco anos mais tarde, em 2014, eram 49.107 cargos efetivos de professor, 66230 cargos designados e 50.471 cargos efetivados, totalizando 165.808 cargos de professor.

Optou-se, deliberadamente, por trabalhar com o número de cargos de professor e não com o número de professores, considerando que um mesmo profissional pode ocupar, ao mesmo tempo, mais de um posto, sendo possível exercer, por exemplo, um cargo efetivo e outro designado. Para se ter uma ideia, em 2014, a rede estadual de ensino de Minas Gerais possuía 165.808 cargos de professor, estes ocupados por 142.331 docentes.

A evolução dos cargos efetivos, designados e efetivados de professor da rede estadual de ensino de Minas Gerais, ao longo de cinco anos, entre 2009 e 2014, é explicitada no Gráfico 1. Tomando como referência o ano de 2009, em 2014, nessa rede de ensino, havia 23.321 cargos efetivos a menos de professor, 31.275 cargos designados a mais de professor, 12.295 cargos efetivados a menos de professor e 4.341 cargos de professor a menos no total.

Em 2009, 42,6\% dos cargos eram ocupados por professores efetivos, enquanto, em 2014, esse valor caiu para 29,6\%. O percentual de cargos ocupados por professores designados saltou de 20,5, em 2009, para 39,9, em 2014. E o número

Tabela 1 - Distribuição dos cargos efetivos, designados e efetivados de professor da rede estadual de ensino de Minas Gerais, por agrupamento docente (2009-2014).

\begin{tabular}{l|c|c|c|c|c|c}
\hline & $\mathbf{2 0 0 9}$ & $\mathbf{2 0 1 0}$ & $\mathbf{2 0 1 1}$ & $\mathbf{2 0 1 2}$ & $\mathbf{2 0 1 3}$ & $\mathbf{2 0 1 4}$ \\
\hline Efetivos & 72.428 & 65.016 & 58.879 & 51.501 & 53.216 & 49.107 \\
\hline Designados & 34.955 & 48.428 & 56.166 & 56.854 & 67.614 & 66.230 \\
\hline Efetivados & 62.766 & 59.875 & 58.328 & 56.461 & 54.109 & 50.471 \\
\hline Total & 170.149 & 173.319 & 173.373 & 164.816 & 174.939 & 165.808 \\
\hline
\end{tabular}

Nota: Foram levantados os dados referentes aos meses de dezembro de cada ano.

Fonte: Secretaria de Estado de Educação de Minas Gerais, 2015b.

Elaboração das autoras. 
de cargos ocupados por professores efetivados oscilou, entre 2009 e 2014, de 36,9\% para 30,4\%. O Gráfico 2 apresenta a rede estadual de ensino de Minas Gerais em números percentuais, entre 2009 e 2014, por agrupamento docente.

Como o número de horas/aula ministrado por um professor, seja ele efetivo, efetivado ou designado, é variável, procurou-se verificar qual a carga horária asse-

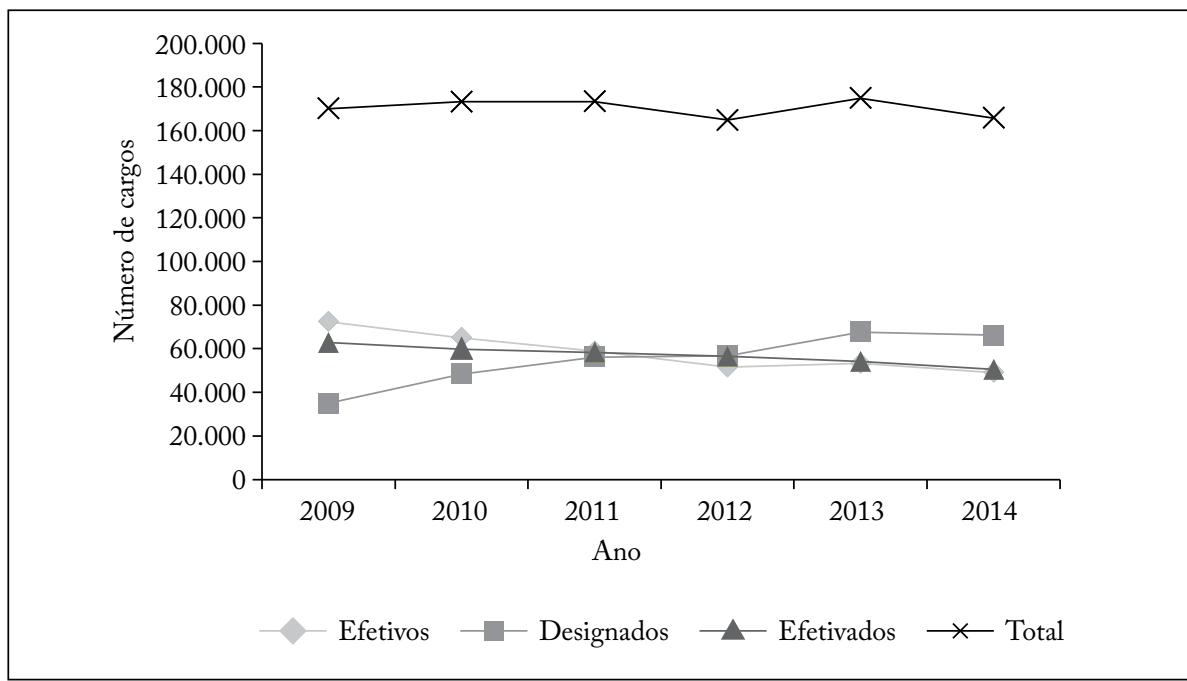

Gráfico 1 - Evolução dos cargos efetivos, designados e efetivados de professor na rede estadual de ensino de Minas Gerais, por agrupamento docente (2009-2014).

Fonte: Secretaria de Estado de Educação de Minas Gerais, 2015b.

Elaboração das autoras.

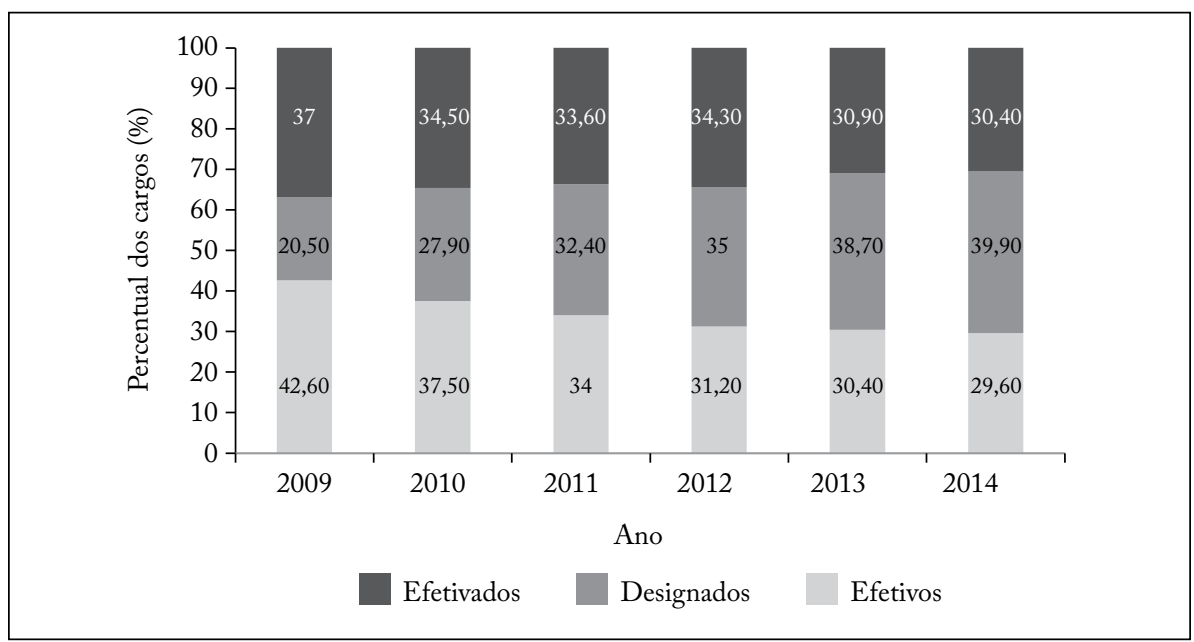

Gráfico 2 - Distribuição percentual dos cargos efetivos, designados e efetivados de professor na rede estadual de ensino de Minas Gerais, por agrupamento docente (2009-2014).

Fonte: Secretaria de Estado de Educação de Minas Gerais, 2015b.

Elaboração das autoras. 
gurada por cada um dos grupos de professores. O Gráfico 3 exibe o resultado desse exercício. Em 2009, na rede estadual de ensino mineira, 52,5\% da carga horária assegurada estavam sob a responsabilidade de professores que ocupavam cargos efetivos, $14,5 \%$, de professores que ocupavam cargos designados e $33 \%$, de professores que ocupavam cargos efetivados. Em 2014, 37,4\% da carga horária assegurada estavam sob a responsabilidade de professores que ocupavam cargos efetivos, $30,9 \%$, de professores que ocupavam cargos designados e $31,7 \%$, de professores que ocupavam cargos efetivados.

A Tabela 1 e os Gráficos 1 e 2 demonstram, claramente, que a rede estadual de ensino de Minas Gerais, em 2009, já possuía uma minoria de cargos de professor ocupados por efetivos (eram 72.428 cargos, o que correspondia a $42,6 \%$ do total) e que, entre 2009 e 2014, de forma paulatina e crescente, os cargos de professor passaram a ser cada vez menos ocupados por professores efetivos (eram então 49.107 cargos, o que equivalia a 29,6\% do total). Em outras palavras, no decorrer de cinco anos, a rede estadual de ensino de Minas Gerais foi tornando-se gradativamente uma rede de ensino dominada por cargos de professores não efetivos.

Além disso, chama atenção o aumento de cargos de professor ocupados por docentes designados, que em 2009 significavam, em números absolutos, 34.955 postos, ou seja, 20,5\% do total deles. Em 2014, os docentes designados significavam, respectivamente, 66.230 e $39,9 \%$ do total de cargos. Trata-se de um considerável aumento na designação, em cinco anos, uma vez que são 31.275 cargos de professores designados a mais e que a representatividade desse grupo perante os outros dois subiu quase $20 \%$.

Quanto aos cargos de professor ocupados por docentes efetivados na rede de ensino mineira, por sua vez, ainda de acordo com os dados apresentados na Tabela 1

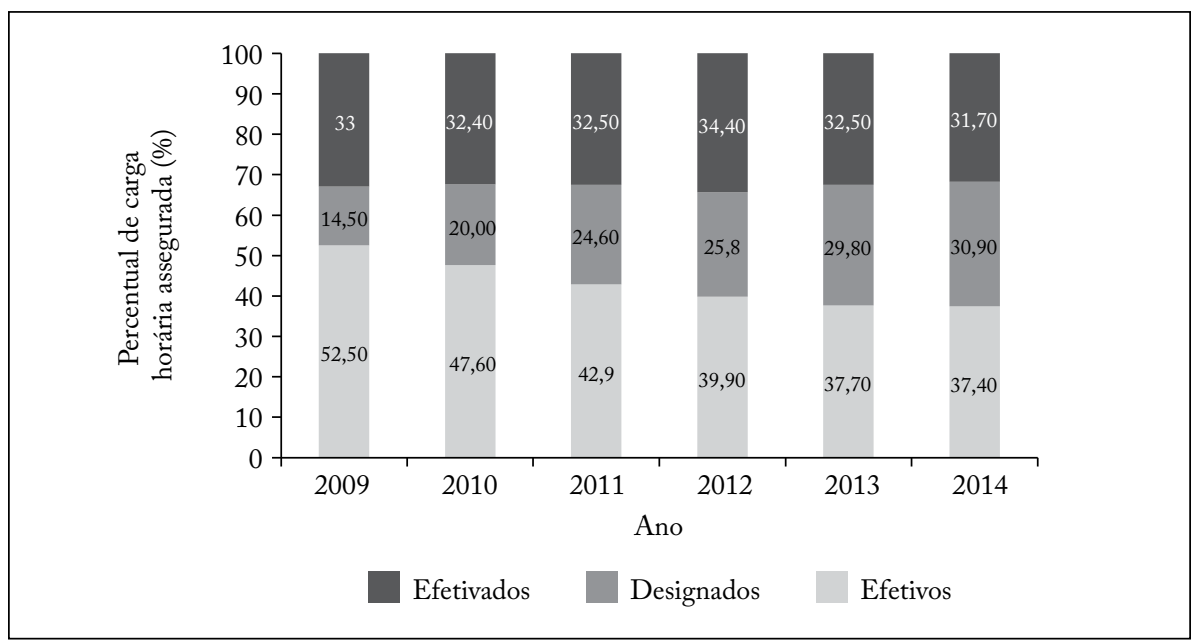

Gráfico 3 - Distribuição percentual de carga horária assegurada por professores que ocupam cargos efetivos, designados e efetivados na rede estadual de ensino de Minas Gerais, por agrupamento docente (2009-2014).

Nota: No levantamento de dados, foi considerado o número de horas/aula por cargo em dezembro de cada ano.

Fonte: Secretaria de Estado de Educação de Minas Gerais, 2015b.

Elaborado pelas autoras. 
e nos Gráficos 1 e 2, a oscilação entre 2009 e 2014, em números absolutos, foi de 62.766 para 50.471 cargos, e, em números percentuais, de $36,9 \%$ para $30,4 \%$ do total de cargos. No entanto, vale lembrar que, no final de 2015, com a denominada "Queda da Lei 100", 9 o governo de Minas Gerais foi obrigado a rever a efetivação inconstitucional da quase totalidade desses professores. Dessa maneira, em 2016, tudo indica que o número de cargos de professor ocupados por professores designados deve ter saltado de praticamente $40 \%$ para $70 \%$. O que se teria, hoje então, seria uma rede de ensino ao avesso, com cerca de $30 \%$ de cargos de professor ocupados por docentes efetivos e por aproximadamente $70 \%$ de cargos de professor tomados por docentes designados, quando o esperado seria quando muito o contrário. Eis aí o que se compreende por "superdesignação".

Por fim, o Gráfico 3 explicita que, quando o que está em questão é a carga horária ministrada e não o número de cargos de professor, a representatividade dos professores efetivos é um pouco maior, enquanto a dos professores designados e efetivados é um pouco menor. Em 2009, 42,6\% dos cargos de professor da rede estadual de ensino de Minas Gerais eram ocupados por efetivos, no entanto os professores que ocupavam esses cargos asseguravam 52,5\% da carga horária da rede. Em 2014, $29,6 \%$ dos cargos de professor eram ocupados por efetivos, assegurando os professores que ocupavam esses cargos $37,4 \%$ da carga horária da referida rede estadual de ensino. Ainda assim, o quadro por carga horária é bastante similar ao de cargo, uma vez que aos efetivos cabe um montante cada vez menor.

É preciso destacar que parte dos professores, certamente, não está em sala de aula, seja porque assumiu responsabilidades de gestão, seja porque se encontra em ajustamento funcional ou por outras razões, o que pode agravar o fenômeno da "superdesignação". A Tabela 2 informa quantos professores em números absolutos e percentuais atuavam ou não na regência de turma por categoria docente, por ano, entre 2009 e 2014. Em 2009, 17.355 cargos efetivos eram ocupados por professores que estavam fora da sala de aula, o que correspondia a $24 \%$ do total dos cargos efetivos existentes. Cinco anos mais tarde, em 2014, embora tenha sido averiguada uma queda no número absoluto, que passou para 14.235, o seu peso diante do total aumentou, alcançando 29\%. Quanto aos cargos designados ocupados por professores que estavam fora da sala de aula, em 2009, eram 1296, e, em 2014, 2.222, o que correspondia, respectivamente, a $3,7 \%$ e a 3,4\% do total dos cargos designados existentes. Em 2009, 3.642 cargos efetivados eram ocupados por professores que estavam fora da sala de aula, o que significava $5,8 \%$ do total de cargos efetivados existentes. Passados cinco anos, em 2014 , esse valor mais que dobrou, chegando a 7.570, algo equivalente a $15 \%$ do total. Conforme é possível observar, são sobretudo os docentes que ocupam cargos efetivos e efetivados que não estão em sala de aula, considerando os números absolutos. Todavia, o impacto dessas ausências sobre o total de cargos é bem maior no caso dos efetivos.

9 No final de 2015, a lei n. 100, de 2007, que efetivou mais de 114 mil servidores, foi declarada inconstitucional pelo Supremo Tribunal Federal (STF), o que levou à dispensa desses servidores. Tal episódio ficou conhecido como "Queda da Lei 100”. A esse respeito, ver Maia (2015). 
O Gráfico 4 apresenta a rede estadual de ensino de Minas Gerais em números percentuais, entre 2009 e 2014, por agrupamento docente, calculando apenas os cargos de professor ocupados por docentes que estavam em sala de aula. Em 2009, $37,50 \%$ dos cargos eram ocupados por professores efetivos que atuavam na regência de turma, enquanto, em 2014, esse valor caiu para $24,47 \%$. O percentual de cargos ocupados por professores designados na mesma situação saltou de $23,92 \%$, em 2009, para 46,53\%, em 2014. E o número de cargos ocupados por professores efetivados em sala de aula caiu, entre 2009 e 2014, de 38,56\% para 28,99\%. Comparando esses dados com os do Gráfico 2, que apresenta a distribuição percentual dos cargos efetivos, designados e efetivados de professor na rede, constata-se que de fato o fenômeno da "superdesignação" é ainda mais grave quando a questão é quem está conduzindo o processo de ensino-aprendizagem cotidianamente nas escolas. Os percentuais de cargos de professor efetivos apontados no Gráfico 2 eram um

Tabela 2 - Professores em cargos efetivos, designados e efetivados da rede estadual de ensino de Minas Gerais que atuam ou não em sala de aula (2009/2014).

\begin{tabular}{l|c|c|c|c|c|c}
\hline \multirow{2}{*}{$\begin{array}{l}\text { Grupo } \\
\text { docente }\end{array}$} & Ano & \multicolumn{2}{c|}{$\begin{array}{c}\text { Em sala } \\
\text { de aula }\end{array}$} & \multicolumn{2}{c}{$\begin{array}{c}\text { Fora de } \\
\text { sala de aula }\end{array}$} & Total \\
\hline \multirow{5}{*}{ Efetivos } & 2009 & 52761 & $72,8 \%$ & 17355 & $24 \%$ & 72428 \\
\cline { 2 - 7 } & 2010 & 45789 & $70,4 \%$ & 17316 & $26,6 \%$ & 65016 \\
\cline { 2 - 7 } & 2011 & 39793 & $67,6 \%$ & 17724 & $30,1 \%$ & 58879 \\
\cline { 2 - 7 } & 2012 & 33108 & $64,3 \%$ & 17046 & $33,1 \%$ & 51501 \\
\cline { 2 - 7 } & 2013 & 36112 & $67,9 \%$ & 16221 & $30,5 \%$ & 53216 \\
\cline { 2 - 7 } & 2014 & 33657 & $68,5 \%$ & 14235 & $29,0 \%$ & 49107 \\
\cline { 2 - 7 } & 2009 & 33659 & $96,3 \%$ & 1296 & $3,7 \%$ & 34955 \\
\cline { 2 - 7 } & 2010 & 46722 & $96,5 \%$ & 1706 & $3,5 \%$ & 48428 \\
\cline { 2 - 7 } & 2011 & 54452 & $96,9 \%$ & 1714 & $3,1 \%$ & 56166 \\
\cline { 2 - 7 } & 2012 & 55626 & $97,8 \%$ & 1228 & $2,2 \%$ & 56854 \\
\cline { 2 - 7 } & 2013 & 66001 & $97,6 \%$ & 1613 & $2,4 \%$ & 67614 \\
\hline \multirow{5}{*}{ Designados } & 2014 & 64008 & $96,6 \%$ & 2222 & $3,4 \%$ & 66230 \\
\hline & 2009 & 54258 & $86,4 \%$ & 3648 & $5,8 \%$ & 62766 \\
\cline { 2 - 7 } & 2010 & 50814 & $84,9 \%$ & 4925 & $8,2 \%$ & 59875 \\
\cline { 2 - 7 } & 2011 & 48452 & $83,1 \%$ & 6627 & $11,4 \%$ & 58328 \\
\cline { 2 - 7 } & 2012 & 44942 & $79,6 \%$ & 8505 & $15,1 \%$ & 56461 \\
\hline \multirow{5}{*}{ Efetivados } & 2013 & 42969 & $79,4 \%$ & 8818 & $16,3 \%$ & 54109 \\
\hline \multirow{5}{*}{} & 2014 & 39878 & $79,0 \%$ & 7570 & $15,0 \%$ & 50471 \\
\hline
\end{tabular}

Notas: 1. No momento do levantamento, foi considerado se o professor ocupante de um cargo estava ou não em sala de aula no mês de dezembro. 2. O total equivale a 100\%. Quando a soma de "Em sala de aula" e "Fora de sala de aula" for inferior ao total, a diferença corresponde aos casos sem informação.

Fonte: Secretaria de Estado de Educação de Minas Gerais, 2015b.

Elaboração das autoras. 
pouco menos baixos que os agora apresentados no Gráfico 4 (respectivamente: 42,60, em 2009; 37,50, em 2010; 34, em 2011; 31,20, em 2012; 30,40, em 2013; 29,60 , em 2014; e 37,50, em 2009; 31,94, em 2010; 27,88, em 2011; 24,76, em 2012; 24,89, em 2013; 24,47, em 2014).

Mas o que explicaria o fato de a rede estadual de ensino mineira possuir tantos professores temporários, sendo que esse contingente, com o passar dos anos, apenas seguiu aumentando? Aparentemente, por detrás desse fato encontra-se outro: os concursos realizados parecem visar apenas preencher vagas de professores efetivos que se aposentam, ou seja, não parecem querer preencher outras vagas, como a de efetivos que se desligam definitivamente da rede de ensino, no caso dos que pedem exoneração, por exemplo, muito menos tentar reverter o quadro de "superdesignação". Entre 2009 e 2014, foram abertas 38.617 vagas por meio de concurso, número pouco superior as 38.330 vagas liberadas por aposentadoria (Tabela 3). ${ }^{10}$

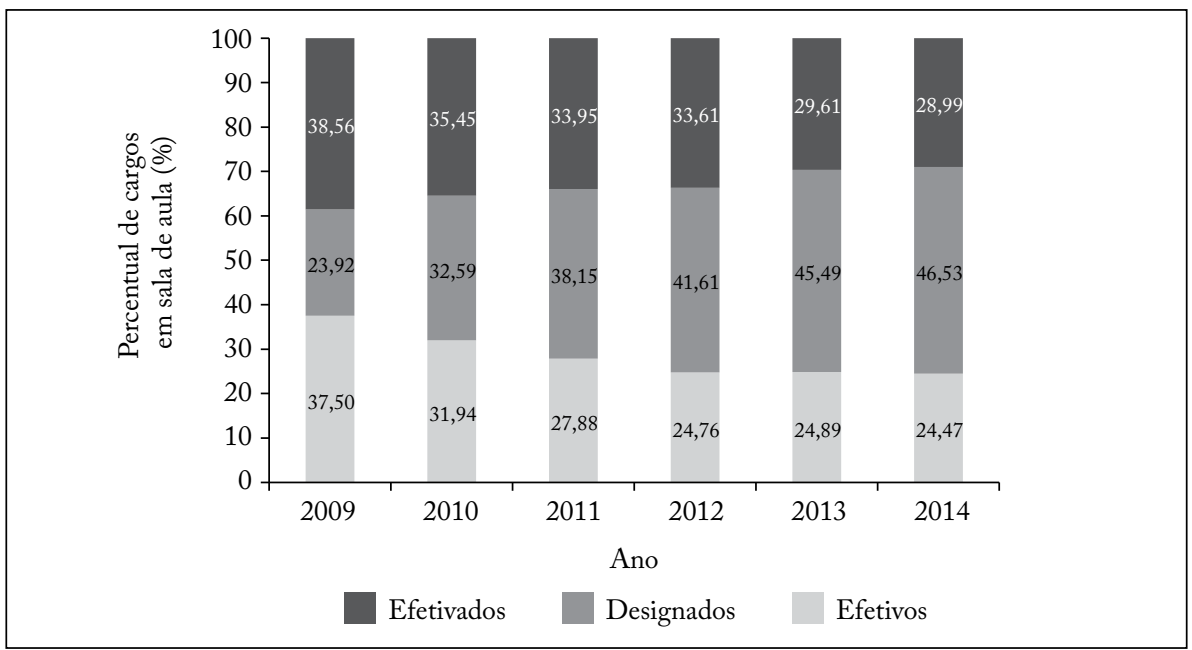

Gráfico 4 - Percentual de professor em cargos efetivos, designados e efetivados da rede estadual de ensino de Minas Gerais que atuam em sala de aula (2009-2014).

Fonte: Secretaria de Estado de Educação de Minas Gerais, 2015b.

Elaboração das autoras.

10 Computadas aposentadoria, exoneração solicitada pelo servidor, exoneração pela administração pública, demissão e abandono de cargo, o total de professores efetivos que se desligaram definitivamente da rede estadual de ensino de Minas Gerais, por ano, entre 2009 e 2014, é: 12.566 , em 2009; 11.369, em 2010; 8.588, em 2011; 8.794, em 2012; 6.528 , em 2013; 6.083, em 2014. Se comparados esses números com aqueles apresentados na Tabela 3, é possível observar que a aposentadoria é a principal razão desses desligamentos: foram 53.928 desligamentos definitivos, entre 2009 e 2014, sendo que, desses, $38.330(71,1 \%)$ foram determinados por aposentadoria. 


\section{HIPÓTESES EXPLICATIVAS DA “SUPERDESIGNAÇÃO” DE PROFESSORES}

Os professores designados da rede estadual de ensino de Minas Gerais, por se tratar de profissionais ao menos teoricamente temporários, possuem menos direitos trabalhistas que os professores efetivos, não tendo acesso, por exemplo, ao deslocamento na carreira de professor. Em razão disso, presume-se que os custos para o governo com um designado são sempre menores que com um professor efetivo. A primeira hipótese então elencada para explicar a "superdesignação" de professores em Minas Gerais é financeira. $\mathrm{O}$ estado possuiria uma rede de ensino composta majoritariamente de professores temporários porque isso lhe custaria menos? Tratar-se-ia de uma questão de economia?

Para construir tal hipótese, é preciso averiguar os gastos da SEE-MG com a remuneração de professores. A evolução da folha de pagamento desses profissionais, nessa rede de ensino, no período que se estende entre 2009 e 2014, calculando apenas os servidores ativos, é apresentada no Gráfico 5 . Em todos os anos, o gasto com os professores efetivos é superior ao despendido com os professores efetivados, que por sua vez é superior ao valor empregado com os designados. Por exemplo, em 2009, no mês de janeiro, empregaram-se $\mathrm{R} \$ 135.067 .518,55$ com os professores efetivos; $\mathrm{R} \$ 74.292 .844,84$ com os efetivados; e $\mathrm{R} \$ 4.433 .661,09$ com os designados. Já em 2014, também no mês de janeiro, o montante gasto com cada um desses grupos de professores foi o seguinte: $\mathrm{R} \$ 197.808 .981,31$ com os efetivos; $\mathrm{R} \$ 126.646 .245,58$ com os efetivados; e R $\$ 103.966 .169,27$ com os designados. A "superdesignação", então, seria explicada pelo fato de possivelmente ser muito menos custoso para o estado contratar professores temporários que investir em um corpo docente permanente?

Outro fator que leva a pressupor que o aspecto financeiro pese sobre a definição da composição do quadro de pessoal da rede estadual de ensino de Minas Gerais,

Tabela 3 - Comparação entre o número de vagas ofertadas em concurso público e o número de professores efetivos aposentados na rede estadual de ensino de Minas Gerais (2009-2014).

\begin{tabular}{l|c|c}
\hline Ano & $\begin{array}{c}\text { Número de vagas ofertadas } \\
\text { em concurso público (a) }\end{array}$ & $\begin{array}{c}\text { Número de professores } \\
\text { efetivos aposentados (b) }\end{array}$ \\
\hline 2009 & 0 & 8.811 \\
\hline 2010 & 0 & 7.946 \\
\hline 2011 & 21.377 & 6.923 \\
\hline 2012 & 0 & 7.289 \\
\hline 2013 & 0 & 4.309 \\
\hline 2014 & 17.240 & 3.052 \\
\hline Total & 38.617 & 38.330 \\
\hline
\end{tabular}

Fontes: (a) Neuenschwander (2015, p. 71); (b) Secretaria de Estado de Educação de Minas Gerais, 2015 b. Elaboração das autoras. 
além da folha de pagamento, é a limitação de $60 \%$ da receita corrente líquida com gastos de pessoal que a Lei de Responsabilidade Fiscal (LRF) impõe aos estados. Tal percentual, em Minas Gerais, de acordo com notícia do Tribunal de Contas do Estado (TCE), de 3 de dezembro de 2015 (Minas Gerais, 2015a), já extrapolou o limite prudencial de $95 \%$ do limite da lei, gastando $46,55 \%$ da receita com recursos humanos. Nomear servidores em número suficiente para reverter o quadro apresentado, então, é muitas vezes legalmente impossível. Ao menos, sem que se deixe de gastar drasticamente com pessoal em outras áreas.

De posse dessas informações, acreditava-se que, na entrevista, o então subsecretário de Recursos Humanos da SEE-MG justificaria o fenômeno da "superdesignação" de professores alegando o custo financeiro de sua reversão e as limitações impostas pela LRF. No entanto, o professor Antônio David de Souza Júnior declarou por detrás do problema não estão somente questões de ordem financeira, sobretudo porque ter uma maioria de professores designados traz prejuízos, inclusive financeiros, para o estado - por exemplo, gasta-se muito dinheiro com a formação continuada de profissionais que estão de passagem pelo serviço público. Por isso, foi construída uma segunda hipótese, de natureza gerencial.

Para o subsecretário, por um lado, a designação constitui um importante mecanismo de gestão para o estado assegurar à população o direito à educação, e é preciso ter em mente que sempre existirão professores contratados por tempo determinado. No entanto, por outro lado, os designados deveriam ser exceção, e não regra, o que terminou acontecendo na rede, uma vez que esse grupo constitui

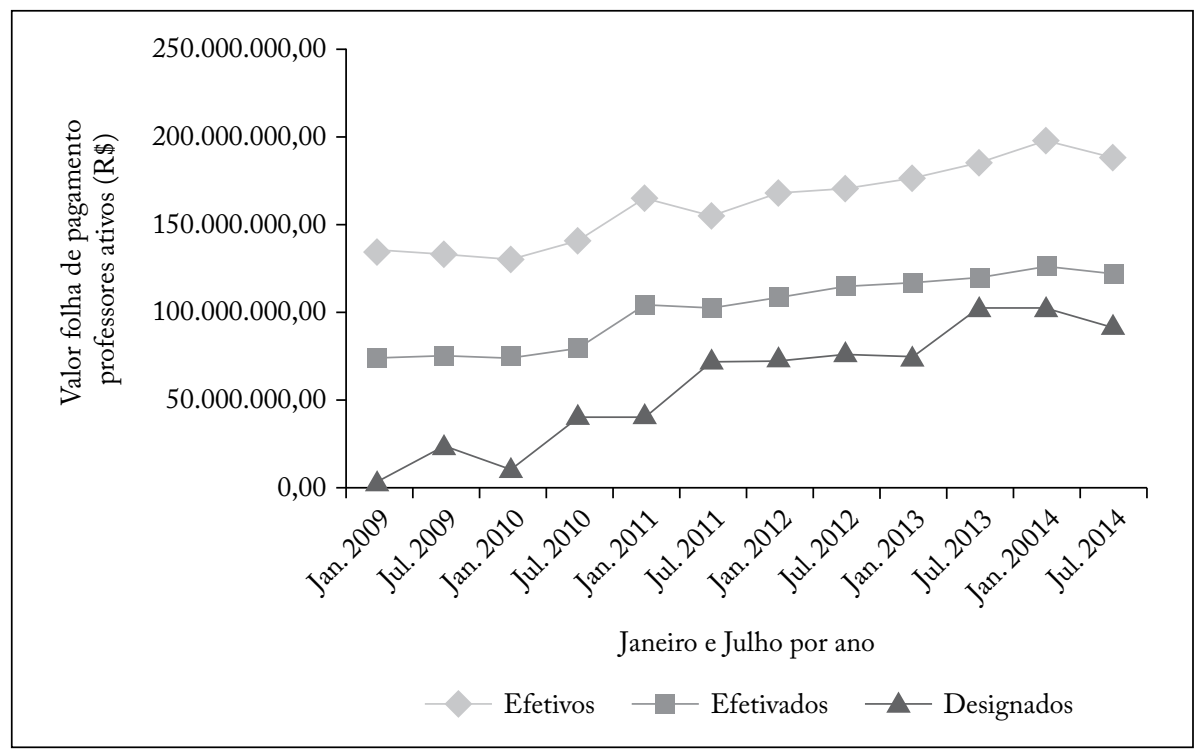

Gráfico 5 - Evolução da folha de pagamento dos professores efetivos, designados e efetivados da rede estadual de ensino de Minas Gerais (2009-2014).

Fonte: Secretaria de Estado de Educação de Minas Gerais, 2015b.

Elaboração das autoras. 
larga maioria. Esse fora um problema, segundo ele, construído ao longo de anos, então de difícil resolução. Em suas palavras, "é um problema estrutural, não apenas do último governo ou dos últimos governos; é um problema que se acumula, há décadas" (Souza Júnior, 2016). Nessa perspectiva, pergunta-se: A “superdesignação" seria fruto de uma série de decisões de gestão tomadas ao longo de sucessivos governos, sendo que, uma vez que o fenômeno se desenhou, ele foi tornando-se cada vez mais definitivo? ${ }^{11}$

Por fim, elaborou-se uma terceira hipótese explicativa sociológica, que também parece ser bastante fecunda, sobretudo se articulada com as duas primeiras. No Brasil, a educação é um direito de todos e um dever do Estado (Brasil, 1988), e o que se tem observado é a expansão da rede de ensino pública voltada para a educação básica e a inclusão na escola de crianças e jovens oriundos das camadas populares da população. Paralelamente, as crianças e os jovens pertencentes às camadas mais privilegiadas, que por muito tempo eram os únicos com acesso à escolarização, foram migrando da rede pública para a rede privada de ensino, fazendo com que, salvo raras exceções, a escolha de matrícula em uma escola pública aconteça quando não se tem condições econômicas para frequentar uma escola particular. A Tabela 4 revela a correlação entre renda familiar e rede de ensino, demonstrando, com clareza, quanto a escola pública de ensino fundamental e médio é, na verdade, a escola para o pobre.

O governo não investiria na constituição de um corpo docente permanente levando em conta o nível socioeconômico dos alunos da escola pública? A "superdesignação" de professores, no fundo, estaria relacionada com um descaso com a educação das camadas populares e com o direito à educação pública, gratuita e de qualidade? Seria possível mencionar a existência de uma escola pobre para os pobres?

\section{EFEITO ESCOLA, EFEITO PROFESSOR, VÍNCULO DE TRABALHO DOCENTE, LEGISLAÇÃO E POLÍTICAS PÚBLICAS}

É ponto pacífico que as condições socioeconômicas e culturais determinam em grande medida as trajetórias escolares dos sujeitos. ${ }^{12}$ Entre o final dos anos de 1950 e a década de 1960, pesquisadores do campo da sociologia da educação des-

11 De acordo com o subsecretário de Recursos Humanos, diante do problema, o então governo de Minas Gerais tinha a pretensão de: (i) melhorar a gestão da designação, de forma que pudesse atribuir maior carga horária de aula para cada professor designado e, consequentemente, diminuir o número desse grupo no quadro docente na rede e o gasto com pessoal, lançando mão do Sistema Online de Designação, implementado no início de 2016; (ii) nomear 60 mil novos professores efetivos, até 2018. A melhoria da gestão dos efetivos, pela atribuição de uma carga horária mínima para cada professor, também poderia ter um impacto positivo, embora não tenha sido uma ação mencionada pelo subsecretário. Além disso, é preciso se ter em conta que a nomeação de uma quantidade expressiva de professores efetivos em três anos tem um risco, na medida em que abrir concurso público com vagas demais também significa menor concorrência e aprovação de candidatos com um menor nível de qualidade.

12 A esse respeito, ver Bourdieu (2006). 
velaram de uma vez por todas a tendência reprodutivista da escola. No entanto, o paradigma da reprodução terminou levando parte desses pesquisadores a investir em estudos acerca da eficácia da escola, com o objetivo de medir o chamado efeito escola sobre os percursos de estudo dos indivíduos e desvendar o que era (e também o que não era) uma escola eficaz na construção de um sucesso escolar, independente da herança familiar, seja do ponto de vista do capital econômico, mas também do ponto de vista do capital social, cultural e simbólico. Trata-se de uma clara tentativa de luta contra o peso do determinismo socioeconômico e cultural no âmbito educacional, já que os estudos da eficácia poderiam levar, em última instância, à produção de políticas públicas preocupadas em garantir o acesso da população a escolas que fazem a diferença e, assim, promover a justiça social (Bressoux, 2011; Lafontaine, 2011).

Mas, afinal, o que se entende por efeito escola? As escolas acolhem alunos diferentes, do ponto de vista socioeconômico e cultural de suas famílias. E grande parte do que os alunos aprendem ali está relacionada com essa pertença de classe social, raça/etnia, gênero, entre outros, sendo apenas uma parte do seu aprendizado obra da escola. O efeito escola é justamente esse aprendizado, que é fruto da ação da própria escola. Ao medir esse efeito, pode-se verificar a capacidade de uma es-

Tabela 4 - Estudantes da rede pública e da rede particular no ensino fundamental, médio e superior, total e respectiva distribuição percentual, segundo os quintos de rendimento mensal familiar per capita - Brasil (2013).

\begin{tabular}{l|c|c|c|c|c|c}
\hline \multirow{2}{*}{$\begin{array}{l}\text { Quintos de } \\
\text { rendimento } \\
\text { mensal } \\
\text { familiar } \\
\text { per capita }\end{array}$} & \multicolumn{2}{|c|}{$\begin{array}{c}\text { Ensino } \\
\text { fundamental }\end{array}$} & \multicolumn{2}{|c}{$\begin{array}{c}\text { Ensino } \\
\text { médio }\end{array}$} & \multicolumn{2}{|c}{$\begin{array}{c}\text { Ensino } \\
\text { superior }\end{array}$} \\
\cline { 2 - 7 } & $\begin{array}{c}\text { Rede } \\
\text { pública }\end{array}$ & $\begin{array}{c}\text { Rede } \\
\text { particular }\end{array}$ & $\begin{array}{c}\text { Rede } \\
\text { pública }\end{array}$ & $\begin{array}{c}\text { Rede } \\
\text { particular }\end{array}$ & $\begin{array}{c}\text { Rede } \\
\text { pública }\end{array}$ & $\begin{array}{c}\text { Rede } \\
\text { particular }\end{array}$ \\
\hline \multicolumn{6}{c}{ Números absolutos (1.000 pessoas) } \\
\hline Total & 25.210 & 3.979 & 7.335 & 1.072 & 1.522 & 4.837 \\
\hline
\end{tabular}

\begin{tabular}{c|c|c|c|c|c|c}
\multicolumn{7}{c}{ Distribuição percentual (\%) } \\
\hline $1^{\circ}$ quinto & 39,5 & 8,4 & 24,5 & 3,7 & 7,2 & 3,7 \\
\hline $2^{\circ}$ quinto & 27,9 & 14,2 & 26,5 & 8,2 & 11,5 & 8,3 \\
\hline $3^{\circ}$ quinto & 16,9 & 16,2 & 21,8 & 11,8 & 17,3 & 15,9 \\
\hline $4^{\circ}$ quinto & 11,3 & 22,1 & 19,0 & 24,1 & 25,2 & 29,1 \\
\hline $5^{\circ}$ quinto & 4,3 & 39,2 & 8,2 & 52,2 & 38,8 & 43,0 \\
\hline
\end{tabular}

Nota: Exclusive as pessoas em famílias sem rendimentos, sem declaração de rendimentos, pensionistas, empregados domésticos e parentes do empregado doméstico.

Fonte: IBGE, 2013.

Elaboração das autoras. 
cola para elevar o nível médio de aprendizado dos alunos de determinada origem socioeconômica e cultural e igualar o dos alunos com origens diferentes (Bressoux, 2011; Lafontaine, 2011).

A eficácia da escola dificilmente pode ser separada da eficiência de seus professores, da eficiência de seus enturmamentos e de outras mais.

Será que o aluno - criança ou adolescente - seria mais bem-sucedido em outra escola, ou em outra turma? Em caso positivo, a quem poderia ser atribuído esse desempenho: ao professor (à influência dos docentes, às suas práticas de ensino), à composição da turma, ou ao clima predominante no interior da turma? (Lafontaine, 2011, p. 279-280)

Apesar dessa dificuldade, estudos têm procurado decompor o efeito escola e vêm demonstrando que, quando vinculado ao efeito professor, ele é significativo no entanto, quando desvinculado, torna-se muito menos significativo. Por esse motivo, tais estudos aventam que o efeito professor seria mais importante que o efeito escola, que ajuda a compor; embora não deixem de questionar se a eficácia dos professores não dependeria diretamente da forma de organização da escola (Bressoux, 2011; Lafontaine, 2011).

Francisco Soares, professor titular aposentado da Faculdade de Educação da Universidade Federal de Minas Gerais e ex-presidente do Instituto Nacional de Estudos e Pesquisas Educacionais Anísio Teixeira (INEP), tem se dedicado aos estudos da escola eficaz no Brasil. Os resultados de suas pesquisas apontam que o efeito escola de estabelecimentos de ensino que possuem professores licenciados em sua área de atuação, ou seja, formados para lecionar a disciplina que efetivamente lecionam, e contratados por período indeterminado, isto é, efetivos, é maior.

Ao se debruçar sobre o Índice de Desenvolvimento da Educação Básica (IDEB), por exemplo, Soares (2016) destacou como três fatores associados podem impactar no desempenho escolar: a complexidade de gestão, a adequação na formação e a regularidade do vínculo. Notem que dois desses fatores dizem respeito a professores: um preocupado com a formação ou não na área de atuação e o outro com o vínculo de trabalho estável ou precário. Segundo o pesquisador, a média do IDEB das escolas públicas que acolhem crianças e jovens de baixo nível socioeconômico varia de 3,3 para 4,0, ou seja, aumenta 0,7 , caso a complexidade de gestão seja alterada de difícil para baixa e a adequação da formação e a regularidade do vínculo seja alterada de baixa para alta. $\mathrm{O}$ aumento verificado é ainda maior em se tratando de escolas públicas que possuem alunos com perfil socioeconômico mediano: o IDEB médio salta de 3,9 para 5,1, isto é,1,1, realizadas tais alterações. Já em se tratando das escolas públicas frequentadas por um corpo discente de alto nível socioeconômico, o aumento também é de 0,7 , no entanto ocorre em um patamar mais elevado, variando de 5,3 para 6,0, diante das mesmas alterações nos três fatores. A Tabela 5 é clara ao mostrar o impacto da complexidade de gestão, da adequação na formação e da regularidade do vínculo no IDEB médio das escolas públicas por nível socioeconômico de seus alunos, com destaque para as atividades de adequação e regularidade. 
A legislação e as políticas públicas educacionais, curiosamente, oscilam entre o reconhecimento e a desconsideração dos resultados das pesquisas sociológicas, no que concerne especificamente à importância dos professores para o aprendizado dos alunos.

Nesse âmbito, Brito (2013) analisou a legislação referente ao ingresso de professores da educação básica das redes públicas, entre 2010 e 2013, em esfera nacional e em doze estados brasileiros - Paraná, Santa Catarina, Rio Grande do Sul, São Paulo, Minas Gerais, Mato Grosso, Mato Grosso do Sul, Piauí, Rio Grande do Norte, Paraíba, Pará e Roraima. O objetivo era verificar a efetivação ou não do dispositivo constitucional que determina o ingresso exclusivo por concurso público - inciso V, artigo 206 da Constituição Federal de 1988. A pesquisadora verificou que, em todos os estados e capitais pesquisados, exceto em Belo Horizonte e Curitiba, onde não são contratados professores temporários, a afirmação da exclusividade de ingresso por concurso público é seguida pela inclusão na legislação de uma série de incisos que permitem a contratação de professores por um período determinado e mesmo a efetivação de professores sem concurso.

Da mesma forma, Brito (2013) aventou que parece existir uma incongruência entre os textos das políticas educacionais e as ações dos governos no campo da educação. Isso porque, embora a pesquisadora tenha a impressão de que um grande número de professores das redes de ensino públicas é contratado temporariamente, quatro das vinte metas do Plano Nacional de Educação (PNE) tratam da valorização dos profissionais da educação, sendo consideradas estratégicas para que todas as outras dezesseis metas do PNE sejam atingidas. Essas quatro metas são as seguintes:

Meta 15: garantir, em regime de colaboração entre a União, os Estados, o Distrito Federal e os Municípios, no prazo de 1 (um) ano de vigência desse PNE,

Tabela 5 - Impacto da complexidade de gestão, da adequação na formação e da regularidade do vínculo no Índice de Desenvolvimento da Educação Básica médio das escolas públicas por nível socioeconômico - Brasil (2013).

\begin{tabular}{l|c|c|c|c}
\hline $\begin{array}{l}\text { Nível } \\
\text { socioeconômico }\end{array}$ & $\begin{array}{c}\text { Complexidade } \\
\text { de gestão }\end{array}$ & $\begin{array}{c}\text { Adequação } \\
\text { na formação }\end{array}$ & $\begin{array}{c}\text { Regularidade } \\
\text { do vínculo }\end{array}$ & $\begin{array}{c}\text { IDEB } \\
\text { médio das } \\
\text { escolas }\end{array}$ \\
\hline \multirow{2}{*}{ Médio } & Difícil & Baixa & Baixa & 3,3 \\
\hline \multirow{2}{*}{ Alto } & Baixa & Alta & Alta & 4,0 \\
\cline { 2 - 5 } & Bifícil & Baixa & Baixa & 3,9 \\
\cline { 2 - 5 } & Difícil & Alta & Alta & 5,1 \\
\hline
\end{tabular}

Fonte: Soares, 2016.

Elaboração das autoras. 
política nacional de formação dos profissionais da educação de que tratam os incisos I, II e III do caput do art. 61 da Lei n. 9.394, de 20 de dezembro de 1996, assegurado que todos os professores e as professoras da educação básica possuam formação específica de nível superior, obtida em curso de licenciatura na área de conhecimento em que atuam.

Meta 16: formar, em nível de pós-graduação, $50 \%$ (cinquenta por cento) dos professores da educação básica, até o último ano de vigência deste PNE, e garantir a todos(as) os(as) profissionais da educação básica formação continuada em sua área de atuação, considerando as necessidades, demandas e contextualizações dos sistemas de ensino.

Meta 17: valorizar os(as) profissionais do magistério das redes públicas de educação básica, de forma a equiparar seu rendimento médio ao dos(as) demais profissionais com escolaridade equivalente, até o final do sexto ano de vigência deste PNE.

Meta 18: assegurar, no prazo de 2 (dois) anos, a existência de planos de carreira para os(as) profissionais da educação básica e superior pública de todos os sistemas de ensino e, para o plano de carreira dos(as) profissionais da educação básica pública, tomar como referência o piso salarial nacional profissional, definido em lei federal, nos termos do inciso VIII do art. 206 da Constituição Federal. (Brasil, 2014, p. 12)

No que se refere à Meta 18, é interessante notar que a primeira estratégia definida para atingi-la consiste em "estruturar as redes públicas de educação básica, de modo que, até o início do terceiro ano de vigência deste PNE, 90\% no mínimo, dos respectivos profissionais do magistério [...] sejam ocupantes de cargos de provimento efetivo" (Brasil, 2014, p. 57).

Conjugando legislação, políticas públicas e impressões, Brito (2013) conclui que parece existir uma distância entre o discurso da valorização dos profissionais da educação e a realidade da prática de desvalorização desses profissionais. O retrato da profissão docente na rede estadual de ensino de Minas Gerais apresentado neste artigo, por trabalhar com dados reais da contratação temporária de professores pela SEE-MG e trazer à tona o fenômeno da "superdesignação" que assola as escolas estaduais de Minas Gerais, permite afirmar com veemência que a distância intuída por Brito (2013) entre discurso e prática de fato existe e é abissal.

\section{CONSIDERAÇÕES FINAIS}

A pesquisa desenvolvida contribui, inegavelmente, com o campo da educação, especialmente com os estudos da sociologia da educação, da profissão docente e das políticas públicas educacionais. Isso porque desvela os números referentes à contratação de professores na rede estadual de ensino de Minas Gerais e vai além da mera apresentação de dados, procurando compreender o significado desses algarismos (financeiro, gerencial e sociológico) e suas consequências para a qualidade da educação. O quadro de "superdesignação" revelado, surpreendente tamanha as 
suas proporções, configura problema grave na gestão em Minas Gerais, o que impõe, tendo em vista a promoção da educação pública, gratuita e de qualidade, um redirecionamento da ação do Estado.

Tal pesquisa também leva à formulação de novas questões. A situação verificada na rede estadual de ensino de Minas Gerais é recorrente no Brasil? Se levantarmos dados no âmbito aqui investigado em cada uma das redes de ensino estaduais do país, o quadro seria similar ao estampado neste artigo, marcado pelo fenômeno da "superdesignação"? Qual o perfil socioeconômico, sociodemográfico, sociocultural e docente dos professores da rede estadual de ensino de Minas Gerais? Haveria diferença de perfil entre os professores efetivos e os temporários que ajudam a compor a rede? Em que medida o perfil dos profissionais poderia ajudar a compreender o panorama de vínculos de trabalho explicitado? Como é, para uma escola estadual mineira, funcionar com um corpo docente composto minoritariamente de professores efetivos e majoritariamente de professores temporários? No cotidiano escolar, do ponto de vista da gestão da escola, do corpo docente, do corpo discente e da comunidade escolar, ou seja, no âmbito microssocial, o que isso significa? Como os formuladores de políticas e os gestores educacionais poderiam trabalhar para desmontar a "superdesignação"? Quais medidas poderiam ser adotadas em curto, médio e longo prazo, com esse objetivo?

Por fim, é preciso ressaltar que, se a pesquisa desenvolvida é original e merece destaque, é porque, no que diz respeito à transparência da informação, ainda temos um longo caminho a percorrer, em Minas Gerais e no Brasil. Dados referentes aos vínculos de trabalho dos professores de uma rede de ensino pública, naquilo que faz referência a cargos, entre outros, deveriam ser facilmente acessíveis no sítio do órgão público responsável pela gestão da rede de ensino. Dessa maneira, não somente pesquisadores, mas também qualquer cidadão, poderiam ter conhecimento da real situação.

\section{REFERÊNCIAS}

Alberti, V. História oral: a experiência do CPDOC. Rio de Janeiro: FGV,1989. 202p. Bourdieu, P. Escritos de educação. 8. ed. Petrópolis: Vozes, 2006. 256p.

Brasıl. Constituição (1988). Constituição da República Federativa do Brasil. Brasília, DF: Senado Federal, Centro Gráfico, 1988.292p.

. Planejando a próxima década: conhecendo as 20 metas do Plano Nacional de Educação. Brasília, DF: Ministério da Educação, Secretaria de Articulação com os Sistemas de Ensino, 2014. 62p.

Bressoux, P. Efeito estabelecimento. In: Zanten, A. (Coord.). Dicionário de educação. Petrópolis: Vozes, 2011. p. 275-279.

Brito, V. L. A. O Plano Nacional de Educação e o ingresso dos profissionais do magistério da educação básica. Educação E Sociedade, Campinas: CEDES, v. 34, n. 125, p. 1.251-1.267, out./dez. 2013. DOI: http://dx.doi.org/10.1590/S010173302013000400012 
IBGE - Instituto Brasileiro de Geografia e Estatística. Pesquisa Nacional por Amostra de Domicílios. Brasil, 2013. Disponível em: <http://www.sidra.ibge.gov.br/pnad/pnadtic/ asp>. Acesso em: 8 jun. 2016.

Lafontaine, D. Efeito sala de aula (efeito turma). In: Zanten, A. (Coord.). Dicionário de educação. Petrópolis: Vozes, 2011. p. 279-284.

Lapo, F. R.; Bueno, B. O. Professores, desencanto com a profissão e abandono do magistério. Cadernos de Pesquisa, São Paulo: Fundação Carlos Chagas; Campinas: Autores Associados, n. 118, p. 65-88, mar. 2003. DOI: http://dx.doi.org/10.1590/ S0100-15742003000100004

Maia, L. S. F. A contratação precária no estado de Minas Gerais a partir do caso da lei complementar n. 100/2007. 2015. 56f. Monografia (Graduação em Administração Pública) - Fundação João Pinheiro, Belo Horizonte, 2015.

Minas Gerais (Estado). Lei n. 10.254, de 20 de julho de 1990. Institui o regime jurídico único do servidor público civil do estado de Minas Gerais e dá outras providências. Diário Oficial de Minas Gerais, Diário do Executivo, Belo Horizonte, p. 3, 21 jul. 1990.

Lei n. 100, de 5 de novembro de 2007. Institui a Unidade de Gestão Previdenciária Integrada - UGEPREVI — do Regime Próprio de Previdência dos Servidores Públicos do Estado de Minas Gerais e do Regime Próprio de Previdência dos Militares do Estado de Minas Gerais e o Conselho Estadual de Previdência CEPREV -, altera a lei complementar n. 64, de 25 de março de 2002, e dá outras providências. Diário Oficial de Minas Gerais, Diário do Executivo, Belo Horizonte, p. 1,6 nov. 2007.

. Lei n. 18.185, de 4 de junho de 2009. Dispõe sobre a contratação por tempo determinado para atender a necessidade temporária de excepcional interesse público, nos termos do inciso IX do art. 37 da Constituição da República. Diário Oficial de Minas Gerais, Diário do Executivo, Belo Horizonte, p. 1, 5 jun. 2009.

TCE emite alertas ao estado por exceder limites de gastos com pessoal e de endividamento. Notícia do Tribunal de Contas do Estado. Belo Horizonte: TCE/ MG, 2015a. Disponível em: <http://www.tce.mg.gov.br/TCE-emite-alertas-aoEstado-por-exceder-limites-de-gastos-com-pessoal-e-de-endividamento-.html/ Noticia/1111621671>. Acesso em: 8 jun. 2016.

. Secretaria de Educação. Subsecretaria de Gestão de Recursos Humanos. SISAP. Belo Horizonte: 2015b. Acesso restrito.

Neuenschwander, J. O. Desafios da profissionalização da administração pública no Brasil: considerações a partir do caso da Secretaria de Estado de Educação de Minas Gerais. 2015. 83f. Monografia (Graduação em Administração Pública) — Fundação João Pinheiro, Belo Horizonte, 2015.

Soares, F. Indicadores de qualidade e equidade na educação básica. In: Sexta com Especialistas. Belo Horizonte: 2016. Não publicado.

Souza Júnior, A. D. Antônio David de Souza Júnior: entrevista [15 abr. 2016]. Entrevistadoras: B. Barreiros e M. Amorim. 1 áudio digital (43 min). 


\section{SOBRE AS AUTORAS}

Marina Alves Amorim é doutora em letras pela Université d'Haute Bretagne (UHB) - Université Rennes 2 (França). Pesquisadora da Fundação João Pinheiro (FJP).

E-mail: marina.amorim@fjp.mg.gov.br

Brenda Borges Cambraia Barreiros é graduada em administração pública pela Fundação João Pinheiro (FJP).

E-mail: brendabcb94@gmail.com

Recebido em 14 de setembro de 2016 Aprovado em 26 de janeiro de 2017 